\title{
A formação continuada de professores e a educação inclusiva sob o prisma do ensino de nove anos e da Base Nacional Comum Curricular
}

\author{
La formación continuada de los docents y la educación inclusiva bajo el \\ prisma de la educación de nueve años y la base curricular nacional común \\ Teachers' in-service programs and inclusive education in the light of \\ elementary school teaching and National Common Curriculum Base
}

\author{
Mirian Saraiva Pureza ${ }^{1}$
}

Elisabeth Brandão Schmidt ${ }^{2}$

\begin{abstract}
Resumo
As análises deste artigo são derivadas do projeto de pesquisa "Políticas públicas para a formação continuada de professores da educação básica (anos iniciais) e os reflexos nas práticas pedagógicas", desenvolvido no Mestrado em Educação na Universidade Federal do Rio Grande- FURG. Apresenta uma análise das políticas públicas para a formação continuada de professores da educação básica após as mudanças implantadas pela ampliação do ensino fundamental para nove anos e, subsequentemente, pelas diretrizes apontadas pela Base Nacional Comum Curricular. Faz ainda um breve exame acerca das políticas públicas voltadas à Educação Inclusiva sob estes dois prismas: Ensino de Nove Anos e Base Nacional Comum Curricular. Os avanços e carências no que se refere à formação continuada e seus reflexos nas práticas pedagógicas estão sendo foco de atenção na pesquisa em desenvolvimento.
\end{abstract}

Palavras-Chave: Base Nacional Comum Curricular; Educação Básica; Ensino de nove anos; Formação Continuada; Políticas Públicas.

\section{Resumen}

Las reflexiones de este artículo se derivan del proyecto de investigación "Políticas Públicas para la formación continuada de profesores de la educación básica (años iniciales) y los reflejos en las prácticas pedagógicas", desarrollado en el Máster en Educación en la Universidade Federal de Rio Grande - FURG. Presenta un análisis de las políticas públicas para la formación continuada de profesores de la educación básica después de los cambios implementados por la ampliación de la enseñanza fundamental a nueve años y, posteriormente, por las directrices apuntadas por la Base Nacional Común Curricular. Hace un breve examen acerca de las políticas públicas dirigidas a la educación inclusiva, bajo estos dos prismas: Enseñanza de Nueve Años y Base Nacional Común Curricular. Los avanzos y carencias en lo que se refiere a la formación continuada y sus reflejos en las prácticas pedagógicas están siendo foco de atención en la investigación en desarrollo.

Palabras claves: Base Nacional Común Curricular; Educación básica; Enseñanza de nueve años; Formación continua; Políticas públicas.

\footnotetext{
${ }^{1}$ Mestranda em Educação pelo Programa de Pós-graduação em Educação - FURG; Rio Grande; RS; Brasil; mirianpureza@ hotmail.com

${ }^{2}$ Doutora em Educação pela Universidade de Santiago de Compostela; Espanha; elisabthlattes@gmail.com
} 


\begin{abstract}
Analyses reported by this paper originate from the research project "Public policies on in-service education for elementary school teachers (early years) and consequences to pedagogical practices", developed in the Master's Program in Education at the Universidade Federal do Rio Grande - FURG, located in Rio Grande, RS, Brazil. It describes and analyses public policies on in-service education for elementary school teachers after changes implemented by the 9-year elementary school and, consequently, by the guidelines of the National Common Curriculum Base. It also examines public policies which aim at Inclusive Education in the light of both the 9year school and the National Common Curriculum Base. Advances and needs of in-service programs and their consequences to pedagogical practices have been the focus of the ongoing study.
\end{abstract}

Keywords: National Common Curriculum Base; Basic Education; 9-year school; In-service education; Public policies.

\title{
1. Introdução
}

Este artigo está circunscrito a reflexões sobre as políticas públicas para a formação continuada de professores da educação básica após a implementação do ensino fundamental de nove anos e, posteriormente, da Base Nacional Comum Curricular. Analisa também as políticas públicas voltadas à Educação Inclusiva sob estes dois prismas: Ensino de Nove Anos e Base Nacional Comum Curricular.

Ao se referir à importância da pesquisa e da formação contínua do professor, Paulo Freire (1997, p.25) afirma que

quem ensina, aprende ao ensinar, e quem aprende, ensina ao aprender. Não há ensino sem pesquisa e pesquisa sem ensino. Enquanto ensino, continuo buscando, procurando. Ensino porque busco, porque indaguei, porque indago e me indago. Pesquiso para constatar, constatando, intervenho, intervindo educo e me educo. Pesquiso para conhecer o que ainda não conheço e comunicar ou anunciar a novidade.

De fato, as demandas cada vez mais urgentes e os novos paradigmas educacionais requerem do professor pesquisa e aperfeiçoamento constante. Os novos contextos sociais exigem um novo paradigma em educação e um professor preparado para esta exigência. Day, ao defender a importância o desenvolvimento profissional docente, sustenta que este

é o processo através do qual os professores, enquanto agentes de mudança, reveem,
renovam e ampliam, individual ou coletivamente, o seu compromisso com os
propósitos morais do ensino, adquirem e desenvolvem, de forma crítica, juntamente
com as crianças, jovens e colegas, o conhecimento, as destrezas e a inteligência
emocional, essenciais para uma reflexão, planificação e prática profissionais
eficazes em cada uma das etapas das suas vidas profissionais. (DAY, 2001, p. 21).

Não se pode conceber que diante das inúmeras mudanças que ocorrem constantemente no cenário educacional o professor não pesquise sobre as mesmas, de forma que possa tomar decisões mais acertadas acerca de suas práticas. 
RELACult - Revista Latino-Americana de Estudos em Cultura e Sociedade

Revista Latinoamericana de Estudios en Cultura y Sociedad | Latin American Journal of Studies in Culture and Society V. 05, ed. especial, abr., 2019, artigo n ${ }^{\circ} 1131$ | claec.org/relacult |e-ISSN: 2525-7870

Por este motivo, cada vez mais a legislação educacional coloca a formação continuada do professor como primordial ao desenvolvimento de uma educação de qualidade.

\section{A Formação Continuada e a Educação Inclusiva sob a perspectiva do Ensino de nove anos e da Base Nacional Comum Curricular}

Analisando a legislação recente, vemos que em 2001, a Lei nº 10.172 aprovou o Plano Nacional de Educação/PNE (2001-2011), onde o Ensino Fundamental de nove anos se tornou meta progressiva da educação nacional. O PNE propôs, em sua Meta 5: "Alfabetizar todas as crianças até, no máximo, os oito anos.”. A Lei n ${ }^{\circ} 11.114$, de 16 de maio de 2005 tornou a matrícula das crianças de seis anos de idade no Ensino Fundamental obrigatória e a Lei $n^{\circ}$ 11.274, de 6 de fevereiro de 2006 ampliou o Ensino Fundamental para nove anos de duração, com a matrícula de crianças de seis anos de idade e estabeleceu prazo de implantação, pelos sistemas, até o ano de 2010.

Com a implementação do ensino fundamental de 9 anos, a partir da lei 11.274/2006, fica evidente a imprescindibilidade de formação continuada para os professores atuantes nos primeiros anos do ensino fundamental. O ingresso das crianças aos seis anos de idade trouxe desafios e especificidades peculiares, tornando esta etapa da educação básica objeto de programas específicos de formação. O documento orientador do Ministério da Educação para a inclusão da criança de seis anos de idade ressalta que a aprendizagem não depende somente da ampliação do tempo na escola, mas “do emprego mais eficaz desse tempo". O documento destaca que

A ampliação do ensino fundamental demanda, ainda, providências para o atendimento das necessidades de recursos humanos - professores, gestores e demais profissionais de educação - para lhes assegurar, entre outras condições, uma política de formação continuada em serviço, o direito ao tempo para o planejamento da prática pedagógica, assim como melhorias em suas carreiras. Além disso, os espaços educativos, os materiais didáticos, o mobiliário e os equipamentos precisam ser repensados para atender às crianças com essa nova faixa etária no ensino fundamental, bem como à infância que já estava nessa etapa de ensino com oito anos de duração.

De fato, a reestruturação dos tempos, espaços e práticas fizeram-se necessárias. Neste sentido, a formação continuada para os professores dos três primeiros anos do ensino fundamental ganha destaque, com programas como o Pacto Nacional Pela Alfabetização na Idade Certa (PNAIC).

O programa do PNAIC não propôs um método específico, mas sugestões metodológicas.

Todo o processo de formação está organizado de modo a subsidiar o professor alfabetizador a desenvolver estratégias de trabalho que atendam diretamente às 
necessidades de sua turma e de cada aluno em particular, em função do desenvolvimento e domínio da língua escrita apresentada por esses alunos, no decorrer do ano letivo. Assim, sugestões de atividades didáticas as mais diversas (situações didáticas, sequências didáticas, projetos didáticos, etc.) são apresentadas ao longo de todo o material de formação. (BRASIL, 2015. Caderno de apresentação. p. 21).

Em 2013, os temas abordados nas formações tratavam de Alfabetização em Língua Portuguesa. Neste ano de formação (2013), com o foco na leitura e escrita, foram destacados como práticas apresentadas no PNAIC a serem adotadas em sala de aula, entre outras, a Leitura Deleite, a sistematização dos planejamentos em Sequências Didáticas e o trabalho com gêneros textuais.

Em 2014, o foco foi a Alfabetização Matemática. As formações incentivaram sobremaneira o trabalho com a matemática de forma contextualizada e ligada as práticas sociais.

Em 2015/2016, os cadernos abordaram a alfabetização com foco na interdisciplinaridade. A ideia apresentada durante os encontros de formação do ano em questão foi a de desconstruir a pratica de fragmentar as áreas de conhecimento, tornando o ensino e a aprendizagem mais efetivos, contextualizados e práticos.

Nos anos de 2017/2018, foram retomados os estudos dos cadernos de 2015 tratando da Alfabetização, com aprofundamentos das temáticas abordadas em anos anteriores.

Certamente, analisando as temáticas estudadas ao longo destes anos de formação, observa-se uma diversidade de aprofundamentos feitos sobre a Língua Portuguesa, a Alfabetização Matemática e a Alfabetização. Todos os temas demonstraram fazer parte do cotidiano escolar, fornecendo aos professores não só embasamento teórico, mas também atividades práticas para desenvolver determinados direitos de aprendizagem.

A Educação Infantil por sua vez ganha menor notoriedade concernente a políticas públicas de formação continuada. Houve um esforço para que o artigo 87, §4 $4^{\circ}$ da Lei 9.394/96 que estabelecia que "até o fim da Década da Educação somente serão admitidos professores habilitados em nível superior ou formados por treinamento em serviço" fosse cumprido. Neste sentido, são instituídos programas de formação inicial do professor atuante na Educação Infantil, a exemplo do ProInfantil - uma parceria entre o Ministério da Educação, estados e municípios. Não obstante, para além da formação inicial, o que se percebe é que os programas de formação continuada para a Educação Infantil são escassos. O Plano Nacional da Educação (PNE 2014-2024) em sua meta 1 passa a propor 
Universalizar, até 2016, a educação infantil na pré-escola para as crianças de 4 (quatro) a 5 (cinco) anos de idade e ampliar a oferta de educação infantil em creches de forma a atender, no mínimo, 50\% (cinquenta por cento) das crianças de até 3 (três) anos até o final da vigência deste PNE.

Somente a partir da necessidade de atendimento dessa meta do PNE o poder público passa a dispensar um olhar especifico sobre a Educação Infantil. O Pacto Nacional pela Alfabetização na Idade Certa (PNAIC), que acontece desde o ano de 2012/2013, insere por fim em sua política de formação, no ano de 2017, a Educação Infantil. A Educação Infantil passa a ser vista, pesquisada, pensada e discutida como, de fato, primeira etapa da educação básica e não mais relegada a um segundo plano.

O material didático-pedagógico apresentado nos oito cadernos, divididos em três unidades temáticas, forneceu subsídios para que as formações continuadas realizadas com os professores propiciassem discussões acerca da relação da criança com a linguagem verbal, bem como o lugar da leitura e escrita na educação infantil. Os temas dos cadernos abordaram "Ser docente na educação infantil : entre o ensinar e o aprender"; "Ser criança na educação infantil: infância e linguagem"; "Linguagem oral e linguagem escrita na educação infantil: praticas e interações"; "Bebês como leitores e autores"; "Crianças como leitores e autores"; "Currículo e linguagem na educação infantil"; "Livros infantis: acervos, espaços e mediações" e "Diálogos com as famílias: a leitura dentro e fora da escola".

Mais imperiosa torna-se a formação continuada de professores frente aos já conhecidos desafios da educação inclusiva, agora sob um novo prisma: a extensão do Ensino Fundamental para nove anos. O programa de formação do PNAIC, já em seu primeiro ano de aplicação com professores (2012/2013), coloca como temas de estudo, reflexão e formação abordagens tais como "Alfabetização para todos: diferentes percursos, direitos iguais", “A heterogeneidade em sala de aula e os direitos de aprendizagem no ciclo de alfabetização", "Currículo inclusivo: o direito de ser alfabetizado", além de um caderno específico versando sobre o tema: "A alfabetização de crianças com deficiência: uma proposta inclusiva". No ano de 2014, as formações com foco na matemática também dispensaram atenção à inclusão sob a temática "Educação matemática inclusiva". Em 2015/2016, com as formações abordando a interdisciplinaridade, vemos igualmente debates com foco nos desafios da educação inclusiva, com a temática "Currículo na perspectiva da inclusão e da diversidade: as Diretrizes Curriculares Nacionais da Educação Básica e o Ciclo de Alfabetização”.

A Base Nacional Comum Curricular (BNCC) desponta neste cenário como atriz principal, tornando a ideia do Ciclo da Alfabetização e as formações do PNAIC coadjuvantes neste ato. Apesar de o objetivo principal da BNCC ser o mesmo do PNAIC, a saber: superar 
as desigualdades e garantir a todos o direito à educação de qualidade, as mudanças nas estruturações dos primeiros anos da alfabetização (a exemplo da retenção que passa a ser no segundo ano e não mais no terceiro) demandam mudanças nas formações continuadas ofertadas.

Surge um novo paradigma educacional a partir da homologação da resolução que define a Base Nacional Curricular da Educação Infantil e Ensino Fundamental (22 de dezembro de 2017), passando a consolidar e estabelecer competências e diretrizes para estas etapas da Educação Básica. Não são desconsiderados nas orientações da BNCC, os artigos 29 e 32 da Lei de Diretrizes e Bases da Educação (LDB), o primeiro definindo que a Educação Infantil tem como finalidade o desenvolvimento integral da criança "em seus aspectos físico, psicológico, intelectual e social", e o segundo determinando que o ensino de 9 anos "terá por objetivo a formação básica do cidadão", desenvolvendo o domínio da leitura, escrita cálculo, dentre outras competências.

A fim de subsidiar os Estados da Federação na revisão ou elaboração de seus currículos em consonância com a BNCC, foi criado o ProBNCC. Este programa prevê assistência primeira às Secretarias de Educação, a fim de que possam orientar e guiar suas redes e professores.

Art. $1^{\circ}$ Fica instituído o Programa de Apoio à Implementação da Base Nacional Comum Curricular - ProBNCC, com vistas a apoiar a Unidade da Federação - UF, por intermédio das Secretarias Estaduais e Distrital de Educação - SEDEs e das Secretarias Municipais de Educação - SMEs, no processo de revisão ou elaboração e implementação de seus currículos alinhados à BNCC, em regime de colaboração entre estados, Distrito Federal e municípios.

A questão da Educação Inclusiva na Base Nacional Comum Curricular ainda tem gerado descontentamentos e desconfortos. Após apresentar tópicos relativos à exclusão de grupos historicamente marginalizados como índios, remanescentes dos quilombolas e afrodescendentes, a BNCC estipula que deve haver um compromisso "com os alunos com deficiência, reconhecendo a necessidade de práticas pedagógicas inclusivas e de diferenciação curricular, conforme estabelecido na Lei Brasileira de Inclusão da Pessoa com Deficiência" (BRASIL, 2016, p. 16). As instituições e entidades que estão engajadas por uma escola inclusiva e democrática, repudiam a utilização deste conceito de diferenciação, quando na verdade o que se busca é a implementação de adaptações e adequações curriculares, quando necessárias. Quando o caso é diferenciar, há separação, limitação e não inclusão. Além disso, a BNCC parece suprimir temas subsidiários ao trabalho da escola, somente focando no Atendimento Educacional Especializado (AEE). De fato, os desafios da educação inclusiva não são completamente contemplados na Base Nacional Comum Curricular, tornando-se 
imperiosa sua discussão e inserção na construção dos currículos escolares, bem como nos programas de formação inicial e continuada de professores.

\section{Conclusões}

Incontestavelmente, a cada mudança no cenário educacional, diferentes paradigmas são propostos e o continuum da formação do professor faz-se primordial. Nessa perspectiva, Nóvoa (1995, p.28) afirma que

A mudança educacional depende dos professores e de sua formação. Depende também da transformação das práticas pedagógicas na sala de aula. Mas hoje em dia nenhuma inovação pode passar ao lado de uma mudança ao nível das organizações escolares e do seu funcionamento. Por isso, falar de formação de professores é falar de um investimento educativo dos projetos de escola.

Torna-se evidente que algumas ações concernentes à formação de professores atuantes na Educação Infantil e Anos Iniciais, bem como aos desafios da educação inclusiva já foram concebidas a partir da implementação do ensino de nove anos. Há, no entanto, tencionamentos e desdobramentos no paradigma contemporâneo da educação brasileira, sob o prisma da Base Nacional Comum Curricular, no que se refere igualmente à formação e a educação inclusiva, que necessitam de discussões e estudos mais aprofundados.

\section{Referências}

BRASIL. Ministério da Educação. Secretaria de Educação Básica. Ensino fundamental de nove anos: orientações para a inclusão da criança de seis anos de idade. Organização Jeanete Beauchamp, Sandra Denise Pagel, Aricélia Ribeiro do Nascimento. -Brasília: Ministério da Educação, Secretaria de Educação Básica, 2007.

.Ministério da Educação. Secretaria da Educação Básica. Base nacional comum curricular. Brasília, 2016.2 DF, em: <http://basenacionalcomum.mec.gov.br/\#/site/inicio>. Acesso em: set. 2018.

Ministério da Educação. Gabinete do Ministro. PORTARIA No 331, DE 5 DE ABRIL $D E$ 2018. Institui o Programa de Apoio à Implementação da Base Nacional Comum Curricular - ProBNCC e estabelece diretrizes, parâmetros e critérios para sua implementação. Diário Oficial da União, Brasília, DF, 06 de abr. 2018.

Secretaria de Educação Básica. Diretoria de Apoio à Gestão Educacional. Pacto Nacional pela Alfabetização na Idade Certa. Interdisciplinaridade no ciclo de alfabetização. Caderno de Apresentação / Ministério da Educação, Secretaria de Educação Básica, Diretoria de Apoio à Gestão Educacional. - Brasília: MEC, SEB, 2015. 
. Ensino fundamental de nove anos: orientações gerais. Brasília, MEC/SEB/DPE/COEF, 2004.

MEC. Secretaria de Educação Básica. Diretoria de Apoio à Gestão Educacional. Pacto Nacional Pela Alfabetização Na Idade Certa. Documento Orientador das ações de formação em 2014. Brasília: MEC, 2014. Disponível em: http://pacto.mec.gov.br/images/pdf/doc_orientador/documento_orientador_2016.pdf. Acesso em outubro. 2018.

Secretaria de Educação Básica. Diretoria de Apoio à Gestão Educacional. Pacto Nacional pela Alfabetização na Idade Certa. Caderno de Apresentação. Brasília: MEC/ SEB, $2015 \mathrm{a}$

MEC. Secretaria de Educação Básica. Diretoria de Apoio à Gestão Educacional. Pacto Nacional pela Alfabetização na Idade Certa. Gestão Escolar no Ciclo de Alfabetização/ Caderno para Gestores. Ministério da Educação, Secretaria de Educação Básica, Diretoria de Apoio à Gestão Educacional. Brasília: MEC/ SEB, $2015 b$.

DAY, Christopher. Desenvolvimento Profissional de Professores: os desafios da aprendizagem permanente. Porto: Porto Editora, 2001.

FREIRE, Paulo. Pedagogia da Autonomia 7ed. São Paulo: Paz e Terra. 1997. GRAZIOLI, Fabiano T.; COENGA, Rosemar E. Literatura Infanto juvenil e leitura: novas dimensões e configurações. Erechim: Habilis, 2014.

NÓVOA, Antônio. Formação de professores e profissão docente. In:

(Coord.) Os professores e a sua formação. 2.ed. Lisboa: Instituto de Inovação Educacional, 1995. p.15-33 